\title{
Reactions of Patients during Pregnancy of the Psychotherapist
}

\author{
Maria Paluszny, M.D., Children's Psychiatric Hospital, Ann Arbor, Michigan \\ Elva Poznanski, M.D., Children's Psychiatric Hospital, Ann Arbor, Michigan
}

\begin{abstract}
A variety of patient reactions to the therapists' pregnancies have been described. Although the reactions varied, the central themes of rejection, sibling rivalry, and oedipal strivings were evident. In addition, material suggesting identification with the therapist and identification with the baby was prominent. The case histories were divided into three categories. The first group illustrated the patient's attempts at solving a childhood conflict by means of reliving it in relation to the pregnant therapist. The second group showed a variety of defensive reactions in response to the therapist's pregnancy. The third group, unlike the previous group, integrated into therapy the new material and affect stimulated by the pregnancy, thus allowing for new insights and therapeutic gains. Although some patients showed a temporary setback in therapy, no permanent regressions were seen.
\end{abstract}

The literature on the emotional aspects of pregnancy focuses mainly on the behavioral reactions of pregnant women relative to themselves and the outcome of the pregnancy. Little has been written about the effects on the therapeutic relationship of a pregnancy of the therapist. With the increasing number of women entering and practicing psychiatry, the situation of the therapist being pregnant is likely to become more common. In addition, the situation created by the pregnancy of the psychotherapist adds another dimension in understanding the psychological reactions to pregnancy.

The authors each carried two pregnancies to term during their psychiatric residencies. During this time they saw both adult and child patients in outpatient and inpatient settings. They were in two different training institutions, and it was not until some years later, when they compared their experiences, that they noted certain similarities. Both authors found significant reactions to their pregnancies on the part of their patients. Naturally, these varied depending on the patient's severity of illness, background, and investment in treatment. However, despite individual variation, similar themes were evoked.

Psychotherapy during the therapist's pregnancy is skewed by several factors. It is not unusual for the psychiatric patient to see his therapist as a mother figure; however, a pregnant therapist intensifies this reaction. Reference has been made to Negro therapists being seen as all-giving mammies [1]. Likewise, a 
pregnant therapist can elicit similar reactions of overindulgence from the patient. A nonverbal communication also exists that the therapist has another existence outside the office, implying a sexual life and family ties. These factors, along with countertransference attitudes, stimulate certain types of material, particularly feelings of rejection, sibling rivalry, and oedipal strivings.

The following case histories are divided somewhat arbitrarily into three categories. The first group illustrates the patient's attempts at solving a childhood conflict by means of reliving it in relation to the pregnant therapist. The second group shows a variety of defensive reactions in response to the therapist's pregnancy. The third group, unlike the previous group, was able to integrate into therapy the new material stimulated by the pregnancy.

\section{Group 1: Attempts at Conflict Resolution}

Tommy, an 11-year-old boy, was admitted to the hospital because of repeated aggressive behavior. When he was 1 year old, his parents divorced, and custody was given the father. Three years later the father remarried; however, the children continued to be cared for by the same housekeeper. At about age 5, Tommy began showing angry outbursts, which progressed until he was ostracized in the neighborhood and expelled from school.

In the hospital, Tommy vacillated between dependent, immature behavior and omnipotent, aggressive behavior. After a few months in the hospital, Tommy formed a positive relationship with his first therapist (a male). He was able to discuss his fears of aggression and feelings of inadequacy. However, when his first therapist informed Tommy of his impending departure Tommy again showed regression to his old behavior.

After reassignment to one of the authors, Tommy appeared to establish a good relationship with his new therapist. His angry outbursts became less frequent, and Tommy was discharged from the inpatient service into a day care program. There he continued to do well until it became obvious that his therapist was pregnant. At this time his outbursts again became frequent. He could not talk about his feelings, but the meaning of his actions was clear. Frequently, while playing pool with his therapist, he retracted the cue so abruptly that the therapist had to dodge in order to avoid being hit in the stomach. During one outburst he hit a pregnant teacher. Tommy raised few questions about the pregnancy, except to wonder when his therapist would be gone and when she would return. A predominant theme in therapy during the author's pregnancy was his brother. When his brother also began psychotherapy Tommy exclaimed with obvious delight, "He needs it more than I do!"

The therapist left abruptly, as her delivery occurred several weeks early. When 
Tommy learned that his therapist had twins, he went to her home and left two baby rattles with a card on the doorstep. He seemed to be saying, "Don't forget about me." On the therapist's return Tommy seemed very pleased to see her, but immediately after his session he had an angry outburst in school.

Tommy used the therapist's pregnancy in an attempt to resolve his feelings of being unloved. The expressions of hostility towards the pregnancy and Tommy's own brother were based partly on sibling rivalry. Perhaps even more important was the fear of abandonment precipitated by the therapist's pregnancy. To master this Tommy actively sought his therapist's return.

Miss C., a 20-year-old pregnant college student, was admitted to the hospital with a history of episodes of depersonalization, promiscuity, and heavy alcohol intake. The patient was the oldest of nine children. She had difficulty getting along with both parents, especially her mother who expected her to spend a major portion of her time caring for the younger children.

Several weeks after admission, Miss C. delivered and gave up her baby for adoption. Approximately one month later her initial therapist left, and she was reassigned to a second therapist (one of the authors).

When Miss C. first noticed her therapist's pregnancy she reacted by saying it was difficult to talk. She wanted to "get away" and began arriving late for appointments and on one occasion ran away from the hospital.

Later this behavior stopped, and the patient began talking of her feelings about her mother, commenting that the therapist reminded her of her mother who was "always pregnant." She felt that the therapist would no longer see her, saying, "Well, you're not going to bring the baby into the office, are you?" Concomitant with this, the patient frequently asked the therapist for passes from the hospital, or in other ways would ask for a "more giving mother."

Miss C. had two different types of reaction: the pregnant therapist represented her own mother and was also a reminder of her own illegitimate pregnancy. She attempted to solve the childhood conflict of rejection by asking her therapist to be a more giving mother. However, she could only handle defensively feelings related to her own pregnancy. (This will be described below.)

\section{Group 2: Defensive Reactions without Conflict Resolution*}

Miss C. discussed her feelings about her own pregnancy with her first therapist (male). When the author became pregnant, her only comment was, "I should be having that baby, not you."

* After this paper was written, Ruth Lax [2] published an article in which she described the defensive reactions of several adult patients to her pregnancy. 
By chance the author worked at the hospital the evening of her own delivery. After returning home a phone call came from the hospital. Miss C. was very anxious and was experiencing severe abdominal pains that felt "like going through labor." Three hours later the author began labor. (Had the patient sensed an earlier onset via primitive identification?) Miss C. had never had these symptoms before nor at any time subsequent to it.

Another adult female patient showed a similar type of identification:

Mrs. A., a 35-year-old social worker, was admitted for the fourth time with a diagnosis of chronic undifferentiated schizophrenia. Mrs. A., an only child whose parents separated when she was 4 years old, spent her early childhood with her mother and maternal grandfather. She recalled that her mother, a strict disciplinarian, frequently told her that "sex was dirty." When the patient married she wanted to have children; however, she had difficulty conceiving, and two pregnancies terminated in spontaneous abortions.

Mrs. A. reacted to her therapist's pregnancy both verbally and somatically. In therapy, she talked about the desire to have a child, her two miscarriages, and her experience with an adoption agency. Concurrent with expressing these feelings, Mrs. A. complained of "vaginal irritation." A pelvic examination revealed no abnormalities. Two months prior to the therapist's due date, she complained of amenorrhea of 45 days duration. A second pelvic examination was also normal. Mrs. A. was then placed on hormones, which failed to induce menstruation. The amenorrhea could have been a side effect of Thioridazine. However, the timing of the amenorrhea suggested at least a partial psychogenic basis. During the amenorrheic phase, Mrs. A. did well. However, following a menstrual period, she became depressed and talked sadly of her jealousy of the therapist and her own wish to have a baby.

In the following case, a psychotic child seemed to extend the notion of the therapist's pregnancy to all women on the staff and possibly even to inanimate objects:

Gene, a 10-year-old psychotic boy, had been in the hospital for 3 years. He had poor impulse control, frequent angry outbursts, and episodes of very regressed behavior, during which he would smear feces or nasal secretions. He used only single words and gestures for communication. Usually Gene looked pleased whenever he saw his therapist on the ward. Upon recognition of the therapist's pregnancy, however, he withdrew from her. As the pregnancy became more noticeable, Gene repeatedly tried to look under the dresses of the female staff on the ward (but never that of his therapist). Each time he would stop his behavior when the staff member assured him that there was no baby underneath her dress and that it was only his therapist who was having the baby. Gene then developed a new mannerism that consisted of "listening" by placing his ear on any flat surface and waiting there momentarily as if listening for something. 
Perhaps he was listening for a baby. While the meaning was never confirmed, the mannerism disappeared after the therapist's delivery.

Another form of denial occurred with one of the authors late in her pregnancy. The author made daily rounds on a ward of very regressed male patients. Usually the patients appeared apathetic, disinterested, and paid little attention to anyone. However, at this time the author was amazed to draw wolf whistles from these patients. One could speculate that this was an expression of an incestuous wish, as well as a denial of the realistically unattractive appearance of the therapist.

Like the above psychotic patients, some neurotic patients could handle the therapist's pregnancy only in a defensive fashion. Possibly in each case the pregnancy symbolized a core part of the patient's psychopathology.

The following adult female patient used reaction formation to handle her painful anger:

Miss R., a 38-year-old virginal woman, had a breast carcinoma which she realized could be fatal. She was assigned to a female therapist because she was so hostile to men that almost no progress could be made in therapy. Initially, the patient related very well and made significant gains in therapy. However, when the therapist's pregnancy became noticeable, the patient again showed tremendous anger and hostility. She saw the baby as new life and contrasted this with her own impending death. Her anger continued to increase until it became an almost impassable barrier in therapy. Shortly before the therapist went on maternity leave, however, the patient showed a complete affective shift. The hostility was no longer seen in therapy sessions, and upon the therapist's departure for maternity leave, the patient left two baby booties she had knitted on the therapist's desk.

Don, a $7 \frac{1}{2}$-year-old boy, was referred because of learning difficulties. He was an immature, anxious boy with some organic difficulties and was the youngest of two children. His mother became acutely diabetic during her pregnancy with Don and had to be delivered by Caesarean section. Four hours after delivery, Don developed respiratory difficulties and was placed in an incubator. Don was repeatedly told by his parents that he had been "all blue" and in an incubator.

Two important themes in Don's therapy were: $(a)$ his fear of being hurt or mutilated; and $(b)$ his ineffective expression of anger. He was fascinated by fights, being a frequent spectator at any neighborhood fight or intently watching violent programs on television.

Don did not recognize his therapist's pregnancy until it was pointed out to him. Initially, he was not able to talk about it. However, later he began asking questions about the delivery. He was particularly interested in whether his therapist would have a Caesarean section and wondered how much this would hurt and how big the scar would be. While talking about this, he became 
extremely anxious and was unable to continue. He was silent for a while, then began talking about his own difficulties shortly after birth, that is, the episode where he was placed in an incubator.

Behind the themes of mutilation projected onto every possible situation lay the image of his own birth-how he was nearly destroyed and the destruction it caused his mother.

\section{Group 3: Integrated Reactions}

In the following two cases, the pregnancy of the therapist was used as a vehicle to express a variety of feelings. In each case, it played an important part in therapy, seemingly acting as a catalyst to bring out affectively ladened material. There is an interesting tendency on the part of the patients to handle the maternal implications of pregnancy first and the sexual implications later.

Robbie, an 11-year-old boy with encopresis and enuresis, had been in treatment with a male therapist for 3 years and with the author for 1 year. Robbie had made slight progress but remained a very anxious boy, with both depressive and compulsive features.

When his therapist began wearing maternity clothes, Robbie made no comment. His reaction on being told was one of surprise, "Oh, you are? Gee, that's great. What are you going to have, a boy or a girl?" About two weeks later his parents noted that Robbie was fighting more than usual with his younger brother. In therapy, Robbie talked a great deal about his younger brother but always in affectionate terms. He raised specific questions about the therapist's pregnancy but found it difficult to share his fantasies. He did comment that he thought the coming baby would be a boy and then picked the name Robbie because "it is a nice name."

When the date was closer, Robbie described in detail the exhibit of the developmental stages at the Chicago Museum of Natural History. He talked quite easily until he reached the point of describing birth itself. Then he became anxious and was unable to continue for several minutes. Later in the same session he talked about a TV show in which he had seen the birth of an elephant: "All elephants stood around in a circle, and this one was in the middle, so you could not see the baby being born." On questioning, Robbie thought the baby came out of the elephant's "side," and he pointed to his thigh.

In subsequent sessions no further headway was made in either getting Robbie's idea about birth and conception or in trying to explain these to him. Finally, at the therapist's suggestion, the parents discussed at home birth and conception with all the children. Robbie appeared especially interested and asked more pertinent questions than any of the other children. In therapy, he 
acknowledged that this discussion had occurred but would not elaborate on it.

Soon after this the therapist left on maternity leave. On her return Robbie stated that he knew she had twins and asked about the mechanics of taking care of two babies, then dropped the subject. However, a change was noted in Robbie's relationship with the therapist. Earlier in therapy Robbie frequently asked to play games; now he never did. Robbie talked in a more mature fashion. Frequently he, commented on his therapist's dress or asked what she thought about a new shirt or a pair of slacks that he wore. School was the main topic, with emphasis on the girls in his class and his teacher. During one session Robbie talked about liking his teacher and then mentioned how uncomfortable it made him feel when he looked down on her. The therapist noticed when Robbie stood next to her that he was now taller than she.

The above case shows a child handling sibling rivalry and identification with the baby, mainly stimulated by the therapist's pregnancy. Although sexual feelings can be vaguely seen during the pregnancy, oedipal strivings become apparent only after the delivery.

In the following case similar material was stimulated in an adult patient:

Miss E., a 21-year-old college student, was seen in outpatient therapy for $1 \frac{1}{2}$ years prior to the therapist's pregnancy. The patient came from a middle-class family and saw her childhood as relatively happy. She had no difficulties in the classroom, but in any dating relationship she experienced anxiety of almost panic proportions. She also had mild episodes of depression.

Before the author's pregnancy was evident, the patient's material indicated an unconscious perception of the pregnancy. She expressed fears that the therapist was going to leave, adding that she thought "little men" were taking the therapist away. She then recalled that as a child she used to keep her hands under the blankets because "little men" would come and cut her hands off. Some time was spent in relating this to masturbation, but later in seeking other associations the patient recognized "little men" as children. She speculated that it may relate to the therapist being a child psychiatrist or perhaps the therapist herself had children, but she quickly dismissed that idea, stating that she did not want to share the therapist with someone else. Several sessions later, the patient commented that the author's new haircut made her "look different," adding that maybe the author was different and would no longer like Miss E. In the next session Miss E. felt very angry but was uncertain of the reason. She had an image of "twisting somebody's head off." She pictured the "somebody" as a child and thought that it might be her brother. In that same session she stated that she was taking a course elsewhere, so that for its duration she would be unable to come for therapy. When it was interpreted to her how the material clearly indicated that she had become aware of the therapist's pregnancy, the patient appeared genuinely surprised. Then Miss E. realized she had been trying to leave therapy before the therapist left her. 
In subsequent interviews, Miss E. felt angry at the therapist and had fantasies of killing both the therapist and the baby. She concluded that she must have felt this same way towards her mother when her brother was born. She recalled seeing her brother when her mother returned from the hospital, with her mother lying in bed, a baby in her arms. Miss E. then had a fantasy of the author lying in bed with her husband and a new baby. In describing this image, Miss E. looked sad and stated that this mental picture made her feel lonely and abandoned, just as she felt with her mother. She added that she did not want to think that her therapist had had intercourse. As the therapist's pregnancy became increasingly visible, Miss E. talked more about feeling left out.

Miss E. made plans to visit her parents during Christmas vacation. In describing her plans, she mentioned painting eggs. It appeared that she was talking about Easter and not Christmas, and she was then able to see that she did not want to think of a baby's birth but preferred to think of death. She also hoped that the therapist would have the baby while she was away, as she would miss less of therapy. Also, if the baby was born at Christmas, it had the implication of signifying a virgin birth.

As the delivery occurred early, the therapist left suddenly. When therapy was resumed, Miss E. explained that she had heard that the therapist had twins. As with other patients, she identified with the therapist's children. Miss E. still occasionally made references to the pregnancy but now linked it more to sexuality, discussing many sexual themes that she had previously avoided.

In the above case a succession of material central to the patient's neurotic conflict was stimulated by the therapist's pregnancy. The patient first experienced sibling rivalry, loneliness, ambivalent feelings towards her mother, denial of sexuality, and finally oedipal feelings and genital sexuality.

\section{Therapists' Reactions}

The therapists' own attitudes and feelings towards the patients during their pregnancies were in some ways complementary to the patients' reactions.

The psychological changes of pregnancy experienced by the therapists produced subtle but definite shifts in attitudes towards the patients, which in turn influenced the content of psychotherapy. Initially, the daydreams and preoccupations of both therapists revolved around a hyperawareness of physiological changes, as well as thoughts and dreams about the baby itself. In fact, the heightened awareness of one's own maternal state seemed to act as an unconscious stimulus to provoke more discussions about children from the patients. For the most part, in the early stages of pregnancy the changes in attitudes towards the patients themselves were relatively subtle. As pregnancy progressed and particularly after the baby became active, both authors noted a 
tendency to withdraw. One of the authors noted a dramatic change and at times commented that she was existing in two worlds simultaneously. In one world, the patient and therapist interacted, and in the other, the mother (therapist) and unborn child. The kicking of the baby constantly acted as a reminder, beckoning the therapist to retreat briefly into the small, inner world. With this therapist, one sensitive and intuitive patient commented that it was like having three people in the room instead of two. This particular therapist noted that she was still genuinely involved with her patients, but it was of less intensity. Hence, feelings of rejection, expressed by many of the patients in terms of competing with the baby for the therapist's attention, had a reality basis.

In the later stages of pregnancy, both authors noted a marked decreased interest in the intellectual side of psychiatry. Their interest in theoretical concepts, new ways of approaching problems, and case reports seemed to be lacking. The inner world beckoned too strongly. After delivery, intellectual curiosity again rebounded but temporarily dropped again during the next pregnancy.

\section{Summary}

A variety of patient reactions to the therapists' pregnancies have been described. Although the reactions varied, the central themes of rejection, sibling rivalry, and oedipal strivings were evident. In addition, material suggesting identification with the therapist and identification with the baby was prominent. Some patients showed a temporary setback in therapy, but no permanent regressions were seen. In one group the patients integrated into therapy the new material and affect stimulated by the pregnancy, thus allowing for new insights and therapeutic gains.

Dr. Paluszny is Assistant Professor, Department of Psychiatry, University of Michigan Medical School, and Assistant Director, Outpatient Department, Children's Psychiatric Hospital, Ann Arbor, Michigan 48104.

Dr. Poznanski is Assistant Professor, Department of Psychiatry, University of Michigan Medical School, and Staff Member, Children's Psychiatric Hospital, Ann Arbor, Michigan 48104.

\section{References}

1. Grier WH: When the therapist is Negro: Some effects on the treatment process. Amer $J$ Psychiat 123 (12):1587-92, 1967.

2. Lax R: Some considerations about transference and countertransference manifestations evoked by the analyst's pregnancy. Int J Psychoanal 50:363-72, 1969. 